\title{
Are There Any Solutions to the Problem of Declining Nephrology Enrolment? A Dialogue Between Two Practicing Nephrologists
}

\author{
Pierre Antoine Brown ${ }^{1}$ and Swapnil Hiremath ${ }^{*}, 2$ \\ ${ }^{I}$ Division of Nephrology, Faculty of Medicine, University of Ottawa, Canada \\ ${ }^{2}$ Clinical Epidemiology Program, Ottawa Hospital Research Institute, Ottawa, Canada
}

\begin{abstract}
Nephrology, the study of kidney diseases, took its birth as a separate specialty many decades ago, and has gradually more in importance, especially with the advent of renal replacement therapy and kidney transplantation. Nephrology also has a strong physiology foundation; indeed an understanding of renal physiology is crucial for dealing with electrolyte and acid-base problems that a physician commonly faces in day-to-day practice. Perhaps this is why it comes as a surprise that the interest in nephrology fellowships is declining - at least in North America. In this article, we present a dialogue between two practicing nephrologists, working at a tertiary care academic Canadian centre, on some potential solutions to this problem.
\end{abstract}

Keywords: Education, kidney, nephrology, nephrology workforce.

\section{INTRODUCTION}

Nephrology, the study of kidney diseases, took its birth as a separate specialty many decades ago, and has gradually grown in importance, especially with the advent of renal replacement therapy and kidney transplantation. Nephrology also has a strong physiology foundation; indeed an understanding of renal physiology is crucial for dealing with electrolyte and acid-base problems that a physician commonly faces in day-to-day life. It has always had the aura as a challenging specialty, which has attracted intelligent, thoughtful, highly committed and hard-working individuals. Perhaps this is why its a surprise that the interest in nephrology fellowships is declining - at least in North America [1]. In this article, we present a dialogue between two practicing nephrologists, working at a tertiary care academic Canadian centre, on some potential solutions to this problem. Though we approach this problem from a Canadian perspective, we think these thoughts are quite generalized and have universal applicability.

SH: Let me start off by doing something we are never supposed to do in marketing: blame the customer. The current crop of medical students and residents have different priorities than we did [2]. When I speak to them, they do not ask me why I chose this specialty, or what it is about nephrology that I love. For the record, I stumbled into nephrology; I first heard of nephrology as a second year medical resident when one of the smartest chief residents I knew, chose to pursue a career in nephrology. The second incident was when we administered life-saving renal replacement therapy to a critically ill patient during my

*Address correspondence to this author at the Division of Nephrology, The Ottawa Hospital, Riverside Campus, 1967 Riverside Drive, Ottawa, Ontario, K1H 7W9, Canada; Tel: 613-738-8400, Ext. 82762; Fax: 613-738-8337;

E-mail: shiremath@toh.on.ca residency. Not only did the patient survive, but I found myself attracted to the exquisite control of fluids and electrolytes that we could achieve in this challenging situation. Contrast my experiences with those of the current generation, where a commonly asked question is "How is your lifestyle as a nephrologist?". As I mention the times I saved a patient from life-threatening conditions [e.g., hyperkalemia, intoxication], they become less focused on the "heroics" of nephrology and increasingly focused on the sleepless nights of the "hero" nephrologist. Invariably, they slink away towards less demanding specialties.

$\boldsymbol{P A B}$ : I think we should not forget that commercial empires, such as Wal-Mart, were built on the premises that, "the customer is always right." [3] Priorities for young professionals are shifting rapidly and drastically. The current cohort of medical students and residents, just like their peers in other professions, care much more about work hours and conditions than they do about income or the satisfaction derived by healing someone or even saving a life [2]. Nephrology needs to adapt to this shifting market. Nephrology will always be an acute specialty with unpredictable hours and the complexity of the kidney will likely lead to the continued perception of nephrology as a difficult field. Nevertheless, we need to adapt to the shifting priorities and values of medical students and do a better job of marketing ourselves. First, we need to think about changing our group practices. They should be large rather than small [so small groups could contemplate consolidation] to mitigate the frequency of call and work outside normal business hours [e.g. evening outpatient dialysis]. We need to move towards practices that facilitate adapting to working in the evening and at night, perhaps by ensuring that one does not have to work at all after a busy night. Moreover, we need to provide a more robust financial incentive for working outside business hours. In terms of marketing, there is no greater satisfaction for me than to care longitudinally for a 
patient from outpatient nephrology clinic to dialysis and ultimately to a transplant. The bond that nephrologists create with their patients is one that lasts for years and often for decades; unlike other internal medicine subspecialties. In nephrology, we have many opportunities to connect with patients, truly know them, their histories, their family and their life. These deep connections are what make it worthwhile on a day-to-day basis to practice nephrology. Let's not forget that we are one of the only specialties that has perfected the art of making sure patients stay relatively healthy despite their end stage organ disease. Rather than shining the light on the complexities of the nephron to attract future candidates, we should perhaps shine the light on what we do best: keeping folks alive!

SH: You are right, of course. I do say that we were perhaps a bit naïve, rushing in based on likes and passions and not looking at the greater picture. This generation of young doctors understands and appreciates the work-life balance better and earlier [2]. We should learn to adapt and change rather than behave like ostriches: with our heads buried in the sand.

Let me then segue into the other point you artfully made. Despite end-stage organ failure we keep our patients relatively healthy. Ever the optimist, you see the glass as being half-full! Let me remind you that a large portion of our time is spent caring for dialysis patients, who have a 5-year survival rate that, among all the cancers, is better than pancreatic cancers only $[4,5]$. These patients have multiple medical problems, are frequent 'fliers' in the emergency rooms $[6,7]$ and often spend a large proportion of their lives living - and dying - in the hospital [8]. Hence, residents are often exposed to the sickest of the dialysis patients in their ward rotations and this paints a bleak picture of the work we do and the kind of patients we see. Indeed we can try harder to get them excited about the fun and challenging electrolyte problems that we see or the patients with acute kidney injury who do get better. I am afraid, however, that they can easily see behind this veneer and recognize the reality of our everyday nephrology practice.

$\boldsymbol{P A B}$ : That's 5 more years than most other specialists can offer! Let's not kid ourselves though; nephrology patients, and in particular dialysis patients, take the bulk of our clinical time and are very ill. It is true that the prognosis for end stage renal disease [ESRD] is terrible and has not improved since dialysis became a widespread treatment for ESRD [over 50 years ago]. Yet, one needs to seriously reconsider one's career choice if s/he enters an internal medicine program thinking $\mathrm{s} / \mathrm{he}$ will avoid sick patients. Despite this fact, the lack of large collaborative trials on possible interventions [other than renal transplantation] to improve survival on dialysis remains our Achilles heel [9, $10]$. We need to work collaboratively to set up large clinical trials that will span many countries and enroll thousands of patients to look at interventions such as hemofiltration or quotidian dialysis that stand a chance of altering a dialysis patient's prognosis [9].

Still I concede that the thought of caring for sick ESRD patients receiving chronic dialysis turns away more than one potential internal medicine resident. This fact is something that no amount of agile marketing will change. Nephrology will never be as sexy or über popular as some other specialties. That notion begs the question: is this really a problem? More to the point: how many Nephrologists do we really need to train?

These questions require answers that, as of yet, have not been tackled in a meaningful way. A big driver of poor enrolment in nephrology programs is a perceived, and I think real, lack of employment opportunities after residency and fellowship. ESRD prevalence grew almost exponentially in the late 90 's and early 2000's but has now reached a steady state $[5,11]$. Since the bulk of our work and income comes from renal replacement therapies, this steady state means that there is little need for additional nephrologists [12, 13]. Simply put, I think we need to start asking ourselves how many nephrologists are needed $[12,13]$. The fear of not knowing whether one will actually find work after investing 2-4 years of nephrology training is, I believe, a very compelling reason why trainees may avoid nephrology.

$\boldsymbol{S H}$ : You make many excellent points. We take care of really sick patients with a high burden of comorbidities, but so do many other specialties [such as oncology] which have, somehow, dodged this bullet of waning interest. Indeed there are many areas where trials can be done and new evidence generated which can help our patients. The \#DreamRCT initiative [14] highlights some of the ideas out there, but, I suspect we shortchange ourselves when we point out the lack of positive trials in nephrology. The lack of beneficial effect seen in many RCTs in our field is not for lack of trying; one can argue that nephrologists doggedly pursue truth, even if it turns out to overturn our prior biases [15-17]. On a cautiously optimistic note, however, the tide may be turning slowly with some recent positive findings [e.g., TEMPO, HDPAL] [18, 19].

The last point about the need for nephrologists is a big issue. The lack of employment opportunities is perhaps a problem unique to Canada at present [12]. In our profession, the laws of supply and demand still work, and one can argue that the declining enrolment in fellowship programs countrywide just reflect a lower demand for nephrologists. Indeed, a survey of Canadian medical students and an analysis of physician workforce suggested that there is a mismatch between medical students' residency and fellowship choices and the demands of the workplace [13]. Specifically, there is a greater need for primary care physicians rather than specialists [13]. Unfortunately, there is a lag period of several years until this information about workforce demand gets across to students and residents considering nephrology. The current and somewhat difficult employment landscape will have changed in the 3 to 6 years during which these trainees complete their residencies and fellowships. There are many reasons why the landscape will change. First, I suspect that the ratio of nephrologists to the ESRD population is still lower in Canada than the US [20]. Secondly, there is a demographic change which is going to have some significant effects. The aging population, fueled by the baby boomers, will swell, as will the ranks of individuals with chronic kidney disease [21]. Thus, even if the incidence rate for renal replacement therapy [RRT] does not increase, the absolute numbers of patients on RRT will rise. Moreover, in most nephrology programs the baby boomers are well represented as staff attending. Some of them - if not all - will be retiring in the next 5 to 10 years, 
opening up a large number of employment opportunities. Third, many of these issues are cyclical - Canada had a doctor shortage not too long ago $[22,23]$, which belabors my point about the disconnect in the timely flow of information between supply and demand. Lastly, with the implementation of the Affordable Care Act [ACA, i.e. 'Obamacare'], my strong suspicion is that there will be a greater need for all doctors, including nephrologists, in the US.

$\boldsymbol{P A B}$ : You make compelling arguments. You are right that the employment situation is fairly unique to Canada, in part because of our relatively good income that is independent of payments for the actual delivery of dialysis. Though I am afraid that the excellent points you raised regarding the laws of supply and demand are academic to sway the minds of young trainees carrying hundreds of thousands of dollars in student loans and facing a choice between nephrology and another subspecialty. I agree that moving south, to US, will likely become a very viable option with the ACA, yet many Canadian-trained physicians [present company included] find working in the US healthcare environment too challenging, having grown up in an essentially bureaucracy-free health care system.

My true goal was to lure you by our job description and workload; something you are skillfully avoided. So I'll take the plunge. My training in a large academic nephrology practice prepared me quite well for independent practice. Renal replacement therapies, transplantation, fluid and electrolytes, ICUs, teaching, writing papers: little scares me any mox. Yet, the dialysis unit still does, because our work in the unit goes well beyond the Kt/V. My training did not prepare me to be a nephrologist, primary care provider, palliative care specialist and, on occasion, vascular surgeon all at once! [24, 25] Most of us spend a disproportionate amount of our clinical time in the unit. Our patients are sick and complex with many active medical problems [24-26]. They spend a large part of their waking hours in a clinic or a hospital hooked to a machine [or at home performing peritoneal dialysis]. Persuading them to see a myriad of other health care providers outside of the time spent doing dialysis is as difficult as having them adhere to a low phosphorus diet! Thus, we invariably expand our role and treat conditions well beyond the scope of our narrow specialtyspecific training by relying upon remotely acquired knowledge from medical school [24, 25]. I think this fact also frightens potential trainees, when they realize how much there is to deal with. I wish I could reassure them that my training prepared me for it. Hence, I think that we need to incorporate a lot more primary care and palliative care in our training. We need to be prepared for what we have to treat and then display that confidence which we sometimes lack. This certainly will make us better role models and entice young trainees. Rounding in the HD unit may not be as thrilling as ballooning and stenting a blocked artery for some, but for me it is way more stimulating and rewarding than the one time fly-by consult.

$\boldsymbol{S H}$ : Let me interject here, since this is an important issue. Indeed, our patients do have multiple comorbid conditions, and they traverse a complex healthcare system requiring assistance at many steps - and it is not just a case of nephrologists providing nephrology and primary care.
This is a challenge which one can look upon as an opportunity. After all, the millennial generation - described as digital natives and perfectionists - have also been characterized as working well in teams and in collaborative settings [2]. Caring for ESRD patients is the perfect example of collaborative care, involving not only established members of the dialysis healthcare team such as dieticians, but others such as pharmacists, social workers, physiotherapists and medical specialists such as geriatrics and palliative care [26]. Perhaps a variation of the patientcentered medical home model from primary care in the form of a 'medical neighbourhood' [27], could be envisioned in the hemodialysis unit.

Additionally, the point about student loans is quite pertinent. If one wants to work in an academic position, completing a nephrology fellowship is necessary, but far from sufficient. With the greater demands of an academic job, it is mandatory now to have additional education and training, often at a Masters level [in clinical or basic research - or education] and sometimes at a doctorate level. This means one has to be prepared to carry his/her debt burden for many more years, which can be stressful and steer potential trainees away from demanding specialties, like ours. Perhaps a financial deferral during the time one is in residency or fellowship could be considered by policymakers?

$\boldsymbol{P A B}$ : Yes, a financial deferral of loans would help, especially in nephrology given that a large number of practices are based in academic hospitals. Talking about debt and income, I have another important point. Just how many sick and complex ESRD patients should/can we care for? In almost all parts of the world, patient load is proportional to income and this is very true for ESRD care. You and I both agree to that, as a whole, the fee-for-service model in medicine is likely the best to enable patients' access to physician services. Yet, I think this model, when it pertains to ESRD care, is detrimental. There is little incentive for us to keep our ESRD practices small, which in turns limits the amount of time we can dedicate to our individual ESRD patients. This is in stark contrast to what I have outlined above in terms of caring well for our patients and why it is actually important to spend a lot of time with each patient. Not surprisingly, there is emerging evidence that greater patient load adversely affects patients outcomes [28]. Perhaps we should think about a different model of remuneration for ESRD that would enable us to keep the patient to $\mathrm{MD}$ ratio at an ideal.

$\boldsymbol{S H}$ : Those are some radical proposals! Let me wade back into some less treacherous waters. Drawing on my experience, the presence of positive role models did play a significant hand in my choice of an internal medicine residency and, subsequently, nephrology fellowship. I don't think the exposure that medical students have to us within the structure of the current medical school curriculum allows these relationships to flower [1]. The emphasis on 'competency-based' curriculum, and the structured nature of the team-based and case-based learning, where all one does is to help students navigate the course material, takes the human element out of the equation. While it may ensure greater competency, it doesn't allow them sufficient exposure to inspiring lectures and the fascinating stories of the grandeur that is nephrology. Perhaps a few sessions 


\section{Medical Education}

- Foster Positive role models early

- Provide broader training (geriatrics, palliative care)

- Arrange for financial assistance during long residency/ fellowship years

- Provide help in planning career/employment choices

\section{Research}

- Perform large collaborative trials

- Study innovative interventions that can impact clinical outcomes

\section{Clinical Practice}

- More emphasis on collaborative care in the dialysis unit

- Adapt working conditions to achieve better work-life balance

- Consider changes to MD: patient ratio

Fig. (1). Potential solutions to the nephrology workforce problem.

where invited stalwarts could give some inspirational talks might do the trick of sparking an interest in a few individuals.

$\boldsymbol{P A B}$ : I agree, we have many idealistic proposals here but if we are serious about reengaging trainees, we will need to make significant changes to the practice of nephrology. Otherwise, nephrology might be condemned to a slow and painful death.

SH and PAB: To summarize, we have laid out some proposals and ideas that may help stem the tide of declining interest in nephrology fellowships (see Fig. 1). First, we need to start early - and emphasize the beauty of nephrology and present role models to medical students who can foster their interests. Second, we should try to work with policy makers to assist in the financial needs of residents and current nephrology fellows. Most importantly, the way nephrology is practiced needs to change and adapt with the changing circumstances and lifestyle preferences of a younger generation.

\section{CONFLICT OF INTEREST}

The authors confirm that this article content has no conflict of interest.

\section{ACKNOWLEDGEMENTS}

Declared none.

\section{REFERENCES}

[1] Jhaveri KD, Sparks MA, Shah HH, et al. Why not nephrology? A survey of US internal medicine subspecialty fellows. Am J Kidney Dis 2013; 61(4): 540-6.

[2] Borges NJ, Manuel RS, Elam CL, et al. Differences in motives between Millennial and Generation X medical students. Med Educ 2010; 44(6): 570-6.

[3] Wikipedia. The Customer Is Always Right. 2014 [Cited 2014 March 5]; Available from: http://en.wikipedia.org/wiki/The custo mer_is_always_right

[4] Siegel R, Ma J, Zou Z, et al. Cancer statistics. 2014. CA Cancer J Clin $2014 ;$ 64(1): 9-29.

[5] USRDS. USRDS 2013 Annual Data Report: Atlas of Chronic Kidney Disease and End-Stage Renal Disease in the United States. National Institutes of Health, National Institute of Diabetes and Digestive and Kidney Diseases 2013 [cited 2014 March 5]. Available from: http://www.usrds.org/2013/pdf/v2_ch5_13.pdf.

[6] Loran MJ, McErlean M, Eisele G, et al. The emergency department care of hemodialysis patients Clin Nephrol 2002; 57(6): 439-43

[7] Weiss SJ, Ernst AA, Ong M, et al. Effect of a social services intervention among 911 repeat users. Am J Emerg Med 2005; 23(4): 492-6.

[8] Murray AM, Arko C, Chen SC, et al. Use of hospice in the United States dialysis population. Clin J Am Soc Nephrol 2006; 1(6): 1248-55.

[9] Inrig JK, Califf RM, Tasneem A, et al. The landscape of clinical trials in nephrology: a systematic review of clinicaltrials.gov. Am J Kidney Dis 2014; 63(6): 771-80.

[10] Strippoli GF, Craig JC, Schena FP. The number, quality, and coverage of randomized controlled trials in nephrology. J Am Soc Nephrol 2004; 15(2): 411-9. 
[11] CORR.2014 CORR Report: Treatment of End-Stage Organ Failure in Canada, 2003 to 2012. Canadian Institute for Health Information. 2014 [Cited: 2014 March 7]. Available from: https:// secure.cihi.ca/estore/productFamily.htm?pf=PFC2481\&lang=en\& media $=0$

[12] RCPSC. What's Really Behind Canada's Unemployed Specialists? : Royal College of Physicians and Surgeons of Canada 2013 [Cited: 2014 2014/03/05]. Available from: http://www.royalcollege.ca/port al/page/portal/rc/advocacy/policy/hrh/examining_specialist_physici an_employment

[13] Scott IM, Wright BJ, Brenneis FR, Gowans MC. Whether or wither some specialties: a survey of Canadian medical student career interest. BMC Med Educ 2009; 9: 57.

[14] Topf J, Weinstein J. Dream RCT Initiative. 2014 [Cited: 2014 March 5]. Available from: http://ukidney.com/special-presentation s/dream-rct-initiative

[15] Eknoyan G, Beck GJ, Cheung AK, et al. Effect of dialysis dose and membrane flux in maintenance hemodialysis. N Engl J Med 2002; 347(25): 2010-9.

[16] Paniagua R, Amato D, Vonesh E, et al. Effects of increased peritoneal clearances on mortality rates in peritoneal dialysis: ADEMEX, a prospective, randomized, controlled trial. J Am Soc Nephrol 2002; 13(5): 1307-20.

[17] Pfeffer MA, Burdmann EA, Chen CY, et al. A trial of darbepoetin alfa in type 2 diabetes and chronic kidney disease. N Engl J Med 2009 ; 361(21): 2019-32.

[18] Agarwal R, Sinha AD, Pappas MK, et al. Hypertension in hemodialysis patients treated with atenolol or lisinopril: a randomized controlled trial. Nephrol Dial Transplant 2014; 29(3): 672-81.
[19] Torres VE, Chapman AB, Devuyst O, et al. Tolvaptan in patients with autosomal dominant polycystic kidney disease. N Engl J Med 2012; 367(25): 2407-18.

[20] Rosenberg ME. Adult nephrology fellowship training in the United States: trends and issues. J Am Soc Nephrol 2007; 18(4): 1027-33.

[21] Carter MR, Kelly RK. Self-reported health status, body mass index, and healthy lifestyle behaviors: differences between Baby Boomer and Generation $\mathrm{X}$ employees at a southeastern university. Workplace Health Saf 2013; 61(9): 409-18; quiz 19.

[22] Collier R. Doctors call for plan to curb physician shortage. Can Med Assoc J 2008; 178(4): 384.

[23] Hollomby DJ. Manpower issues outside the U.S. Canada looks at its supply of nephrologists. Nephrol News Issues 1998; 12(4): 15-7.

[24] Berns JS, Szczech LA. What is the nephrologist's role as a primary care provider? We all have different answers. Clin J Am Soc Nephrol 2007; 2(3): 601-3.

[25] Zimmerman DL, Selick A, Singh R, et al. Attitudes of Canadian nephrologists, family physicians and patients with kidney failure toward primary care delivery for chronic dialysis patients. Nephrol Dial Transplant 2003; 18(2): 305-9.

[26] Bechade C, Daireaux G, Henri P, et al. Who is the physician in charge with the primary care of the dialysis patients?. Nephrol Ther 2014; 10(2): 106-11.

[27] Greenberg JO, Barnett ML, Spinks MA, et al. The "medical neighborhood": integrating primary and specialty care for ambulatory patients. JAMA Intern Med 2014; 174(3): 454-7.

[28] Harley KT, Streja E, Rhee CM, et al. Nephrologist caseload and hemodialysis patient survival in an urban cohort. J Am Soc Nephrol 2013; 24(10): 1678-87.

(C) Brown and Hiremath; Licensee Bentham Open.

This is an open access article licensed under the terms of the Creative Commons Attribution Non-Commercial License (http://creativecommons.org/licenses/by-nc/3.0/) which permits unrestricted, non-commercial use, distribution and reproduction in any medium, provided the work is properly cited. 